\title{
The Long-Term Development Planning of Energy Critical Infrastructures of Vietnam
}

\author{
Alexei Edelev \\ Melentiev Energy Systems Institute \\ of Siberian Branch of the Russian \\ Academy of Sciences \\ Irkutsk, Russia \\ flower@isem.irk.ru \\ Nguyen Hoai Nam \\ Institute of Energy Science of \\ Vietnamese Academy of Science \\ and Technology, IES VAST \\ Hanoi, Vietnam \\ nhnam@ies.vast.vn
}

\author{
Dmitriy Karamov \\ Melentiev Energy Systems Institute \\ of Siberian Branch of the Russian \\ Academy of Sciences \\ Irkutsk, Russia \\ dmitriy.karamov@mail.ru \\ Nguyen Hong Anh \\ Institute of Energy Science of \\ Vietnamese Academy of Science \\ and Technology, IES VAST \\ Hanoi, Vietnam \\ nhanh@ies.vast.vn
}

\author{
Doan Van Binh \\ Institute of Energy Science of \\ Vietnamese Academy of Science \\ and Technology, IES VAST \\ Hanoi, Vietnam \\ doanbinh@ies.vast.vn \\ Nguyen Viet Huong \\ Institute of Energy Science of \\ Vietnamese Academy of Science \\ and Technology, IES VAST \\ Hanoi, Vietnam \\ nvhuong@ies.vast.vn
}

\begin{abstract}
Renewable energy sources help increase the energy supply security and reduce greenhouse gas emissions in Vietnam. Highly variable and stochastic nature of renewable energy sources poses some challenges to study the problem of generation expansion planning for long-term perspective. The proposed multiobjective model for generation expansion planning considers the fuel restrictions on the power generation and transmission network to measure the geographical impact of the generation additions. Its objectives are minimization of investment, operation and transmission costs, environmental impact, imports of fuel and unmet demand cost Also the model takes into account the following types of constraints: flow balance constraints in the network with demand covering, power generation and transmission limit, generation and transmission investment, availability of local production of fossil fuels, system reliability requirements, maximum and minimum shares of RE resources, energy supply security requirements.
\end{abstract}

Keywords- generation expansion planning, renewable energy, long-term energy development, power system, decision support

\section{INTRODUCTION}

Renewable energy (RE) sources as a part of national energy critical infrastructures would have great influence on the economy of Vietnam [1, 2]. First, RE help increase the diversity of energy supplies, and thus improve the energy supply security. Second, RE might reduce local and global greenhouse gas emissions.

But growth in RE has increased the complexity of the power system operation. Due to the highly variable and stochastic nature of RE, there are concerns over the potential operational and economic impacts of RE sources on the operation and development of the power system [2].

There are a lot of modelling tools to understand the impacts of investing in RE technologies [3]. Generally, the modelling tools can be divided into power system models and energy system models [4]. The power system models simulate the operation of a power system, given a certain power mix, over a relatively short period, typically one year but at high temporal resolution, typically sub-hourly. The longterm energy system optimization models perform the multi-year analysis of the evolution of a system paying into attention changes in technologies and fuel prices without accounting for details of power system operation.

However, highly variable and stochastic nature of RE sources poses some challenges to energy system models to study the problem of generation expansion planning (GEP) for long-term perspective due to using a low temporal resolution and neglecting the shortterm dynamics [5]. It leads to sub-optimal investments, a considerable operational costs underestimation. Finally, both the impact of the temporal resolution and the inclusion of technical detail are increased with the share of RE sources in the power system.

The hybrid approach to withstand those challenges is the linking energy system and power system models, with or without feedback between both models. The main advantages of such hybrid approach are simplicity, computational tractability and use of well-known modelling packages [4]. The soft-linking the Vietnam energy sector model with the power system reliability model should assess RE integration into power system of Vietnam [2].

The GEP problems have usually been modelled as single-objective programming problems which regard only the total cost minimization [6]. In this paper, instead of soft-linking energy system and power system models a multi-criteria approach for GEP problems is considered to work on different objectives: the fuel and technical constraints on the Vietnamese power system operation, the requirements of electricity supply security and power system reliability. 


\section{Multi-OBJECTIVE GENERATION EXPANSION MODEL}

The following multi-objective model for generation expansion planning (MGEP) model is intensively based on the work [7]. The additional objectives and constraints are adopted from studies [810].

The simplified structure of energy sector of Vietnam in the MGEP model is represented as a network $\mathrm{G}=(\mathrm{N}, \mathrm{A})$, where $\mathrm{N}$ is the set of the nodes and $A$ is the set of arcs. The node $i \in N$ represents a point of demand and/or supply of energy, and the arc $(i, j) \epsilon$ $\mathrm{A}$ is a transmission line. A set of power generation technologies $\mathrm{O}$ consists of two subsets: fossil fuel fired facilities and RE sources. R denotes the RE subset. The fossil fuels constitute the set F. $q \in O$ is a power generation technology and $\mathrm{k} \in \mathrm{F}$ is a fossil fuel. $\mathrm{T}$ is the set of periods (hours) in the planning horizon where $t \in \mathrm{T}$ is a time period.

There are some groups of decision variables in the MGEP model: giqt is the generation amount (MW) of technology $\mathrm{q}$ at node $\mathrm{i}$ in period $\mathrm{t}$; $\Delta$ giqt is the capacity addition (MW) of technology $\mathrm{q}$ at node $\mathrm{i}$ in period $\mathrm{t}$; yiqt is the total capacity (MW) of technology q at node $\mathrm{i}$ in period $\mathrm{t}$; $x$ ijt is the flow (MW) through arc $(\mathrm{i}, \mathrm{j})$ in period t; $\Delta x$ ijt is the additional transmission capacity (MW) in arc (i, j) in period t; pijt is the total capacity (MW) in arc ( $i, j$ ) in period $t$; ukt is the imported fuel (kTOE) of type $\mathrm{k}$ in period $\mathrm{t}$; and vit is the unmet demand (MW) at node $i$ in period $t$.

\section{A. Objectives}

There is a set of $L$ objectives in the MGEP model: minimization of investment, operation and transmission costs, environmental impact, imports of fuel and unmet demand cost. A detailed description of each objective is provided below.

- Investment, operational, and transmission costs [7]: This objective function is defined as the total present value sum of the investment cost for new technologies and additional capacity of transmission, the operation and maintenance costs

$$
\begin{gathered}
f_{1}=\sum_{t \in T}(1+r)^{-t}\left[I_{t}+O M_{t}\right], \\
I_{t}=\sum_{i \in N} \sum_{q \in O} S_{i q t} \Delta g_{i q t}+\sum_{(i, j) \in A} C_{i j t} \Delta x_{i j t}, \\
O M_{t}=\sum_{i \in N} \sum_{q \in O} Q_{i q t} g_{i q t} .
\end{gathered}
$$

In this objective, $r$ is the discount factor (rate of return) per unit time on investment, $S_{i q t}$ is the investment cost (\$/MW) of technology $q$ at node $i$ in period $t, Q_{i q t}$ is the operation and maintenance cost (\$/MW) of a technology $q$ at node $i$ in period $t$ and $C_{i j t}$ is the investment cost $(\$ / \mathrm{MW})$ for new transmission capacity in $\operatorname{arc}(i$, $j$ ) in period $t$. The first part $I_{t}$ of the objective function (1) is the investment cost associated to new generation units and transmission facilities; the second part $O M_{t}$ is the operational cost of the system in period $t$.

- Environmental impact [7]: This objective minimizes the environmental impacts

$$
f_{2}=\sum_{t \in T} \sum_{i \in N} \sum_{q \in O} E_{q t} g_{i q t}
$$

where $E_{q t}$ is the amount (tons) of carbon dioxide emission $\mathrm{CO}_{2}$ per MW generated by a technology $q$ at node $i$ during period $t$. The emission of pollutants like $\mathrm{NO}_{\mathrm{x}}$ and $\mathrm{SO}_{2}$ can be also included if necessary [8].

- Fossil fuel import [7]: The goal is to minimize the total amount of fuel imports

$$
f_{3}=\sum_{t \in T}(1+r)^{-t}\left[\sum_{k \in F} U_{k t} u_{k t}\right]
$$

where $U_{k t}$ is the cost (\$/kTOE) of fuel $k$ import in period $t$.

- Unmet demand [8]: The goal is to minimize the total power shortage

$$
f_{4}=\sum_{t \in T}(1+r)^{-t}\left[\sum_{i \in N} V_{t} v_{i t}\right]
$$

where $V_{t}$ is the cost ( $\left.\$ / \mathrm{MW}\right)$ of not satisfying the demand in period $t$.

\section{B. Constraints}

The following types of constraints are presented in the MGEP model: flow balance constraints in the network with demand covering [7], power generation and transmission limit [7, 9], generation and transmission investment [7], availability of local production of fossil fuels [7], system reliability [10], maximum and minimum shares of RE resources [10], energy supply security [10]

- Node power balance equation [7]: The inflow (generation plus flow from other nodes) is equal to the outflow (sum of demand, shortage and flow to other nodes) at node $i \in N$ in period $t \in T$ :

$$
\sum_{(j, i) \in A} x_{j i t}-\sum_{(i, j) \in A} x_{i j t}+\sum_{q \in O} g_{i q t}=D_{i t}+v_{i t}
$$

where $D_{i t}$ is the load/demand (MW) at node $i$ in period $t$.

- Maximum investment for each technology $q$ in node $i$ during period $t$ [7]: There is a maximum value of capacity (or investment) in 
technologies because of natural reasons (space, resources, etc.)

$$
\Delta g_{i q t} \leq G_{i q t} ; i \in N, q \in O, t \in T
$$

where $G_{i a t}$ is the maximal capacity (MW) for new units of technology $q$ in node $i$ during period $t$.

- Fossil fuels demand in period $t$ [7]: Fuel $k$ will be either imported or taken from local markets

$$
\sum_{i \in N} \sum_{q \in O} W_{q t} g_{i q t} \leq u_{k t}+B_{k t} ; k \in F, t \in T
$$

where $W_{q t}$ is the consumption of fuel (kTOE/MW) for a technology $q$ in period $t, B_{k t}$ is the local production (kTOE) of fuel $k$ in period $t$.

- Total generation capacity on each technology q in node i during period $t$ [7]: The total available generation value is equal to the sum of existing generation capacity and the new added capacity

$$
y_{i q t}=y_{i q(t-1)}+\Delta g_{i q t} ; i \in N, q \in O, t \in T \text {. }
$$

- Power generation limit on each conventional technology $q$ in node $i$ during period $t$ [7]:

$$
g_{\text {iqt }} \leq y_{i q t} ; i \in N, q \in O \backslash R, t \in T
$$

- Power generation limit on each RE technology $q$ in node $i$ during period $t$ [9]:

$$
g_{\text {iqt }} \leq H_{i q t} y_{i q t} ; i \in N, q \in R, t \in T
$$

where $H_{i a t}$ is the corresponding hourly capacity factor for each RE technology $q$ in node $i$ during period $t . H_{\text {iat }}$ depends on the weather conditions

$$
0 \leq H_{i q t} \leq 1 ; i \in N, q \in R, t \in T \text {. }
$$

- Total transmission capacity on each arc $(i, j)$ in period $t$ [7]: The total available capacity of the arc $(i, j)$ is equal to the sum of total capacity at $(t-1)$ and the new transmission capacity added at period $t$

$$
p_{i j t}=p_{i j(t-1)}+\Delta x_{i j t} ;(i, j) \in A, t \in T
$$

- Power transmission limit on each arc $(i, j)$ in period $t[7]$

$$
x_{i j t} \leq p_{i j t} ;(i, j) \in A, t \in T .
$$

- Power system reliability [10]: To ensure that the available generation capacity of power system is adequate to meet the expected power demand, the available system capacity in each period $t$ should be between the defined upper and lower bounds as

$$
\begin{gathered}
\sum_{i \in N} \sum_{q \in O} y_{i q t} \leq \sum_{i \in N} D_{i t}(1+\text { PRRMAX }), \\
\sum_{i \in N} \sum_{q \in O} y_{i q t} \geq \sum_{i \in N} D_{i t}(1+\text { PRRMIN }),
\end{gathered}
$$

where PRRMAX is the maximum peak reserve requirement $(\%)$, PRRMIN is the minimum peak reserve requirement $(\%)$.

- RE share [10]: To impose minimum of power generated from RE technologies and to determine the RE sources penetration limits to preserve the power system stability the value of RE sources share in the total system generation at each period $t$ should be between the defined lower and upper bounds as

$$
\begin{aligned}
& \sum_{i \in N} \sum_{q \in R} g_{i q t} \geq \operatorname{MINRE} \sum_{i \in N} \sum_{q \in O} g_{i q t}, \\
& \sum_{i \in N} \sum_{q \in R} g_{i q t} \leq M A X R E_{t} \sum_{i \in N} \sum_{q \in O} g_{i q t},
\end{aligned}
$$

where $M I N R E_{t}$ is the minimum share of $\mathrm{RE}$ sources $(\%)$ in the total system generation in period $t$, $M A X R E_{t}$ is the maximum share of RE sources (\%) in the total system generation during period $t$.

- Energy supply security [10]: to ensure technology variability the available system capacity of technology $q$ may not exceed the upper bound in each period $t$

$$
\sum_{i \in N} y_{i q t} \leq Y_{q t}
$$

where $Y_{a t}$ is the given maximum system capacity of technology $q$ during period $t$.

- Nonnegativity: No negative values are permitted for the decision variables

$$
y_{i q t}, g_{i q t}, \Delta g_{i q t}, p_{i j t}, x_{i j t}, \Delta x_{i j t}, u_{k t}, v_{i t} \geq 0 \text {, }
$$

where $i \in N, q \in O,(i, j) \in A, k \in F, t \in T$.

- Initial values: The generation capacity of technology $q$ in node $i$ in period 0 is equal to $y_{i a}$, the existing generation capacity (MW)

$$
y_{i q 0}=y_{i q} ; i \in N, q \in O \text {. }
$$

- The transmission capacity of $\operatorname{arc}(i, j)$ in period 0 is equal to $p_{i j}$, the existing capacity of transmission (MW) 


$$
p_{i j 0}=p_{i j} ;(i, j) \in A \text {. }
$$

\section{PROBLEM FORMULATION}

Let $\mathrm{fl}(\mathrm{z})$ be the 1-th objective function, $\mathrm{z}$ be decision vector belonging to the feasible solution space Z, i.e.,

$$
z=\left(g_{i q t}, \Delta g_{i q t}, y_{i q t}, x_{i j t}, \Delta x_{i j t}, p_{i j t}, u_{k t}, v_{i t}\right)
$$

where $l \in L, i \in N, q \in O,(i, j) \in A, k \in F, t \in T$. The general MGEP model is a multi-objective linear programming problem

$$
\begin{gathered}
\min F(z)=\left[f_{1}(z), \ldots, f_{L}(z)\right] \\
\text { s.t. } \quad h_{n}(z)=0 ; n \in M_{h} \\
g_{m}(z) \leq 0 ; m \in M_{g} \\
z \in Z
\end{gathered}
$$

where $F$ is the objective vector. $g_{m}(z)$ is the $m$-th inequality constraint, $h_{n}(z)$ is the $n$-th equality constraint, $M_{h}$ and $M_{g}$ are the number of equality and inequality constraints, respectively.

The MGEP model has $|T|(3(|N||O|+|A|)+|F|+|O|)$ variables and $\quad|T|(|N|+2|A|+3|N||O|+|F|+4+|O|)$ constraints.

\section{CLIMATIC DATA GATHERING AND PROCESSING}

To analyse the RE technical efficiency $H_{\text {iat }}$ the necessary detailed climatic information includes solar radiation (direct, diffuse and summary), wind speed and direction, air temperature, density, pressure, humidity and cloudiness. These data allow modelling the solar and wind power plants operation with high accuracy.

Nowadays, there are a large number of different sources to reproduce the original climatic arrays. The most common database is NASA SSE that allows developing the initial climatic data arrays for any location. In addition, there are also available the open online sources like NREL-SWERA, Renewables.ninja for solving similar problems. These sources are based on data from NASA MERRA reanalysis [11] and CMSAF's SARAH dataset [12].

\section{A. Long-term meteorological observation data}

The multiyear meteorological series recorded at the meteorological station are detailed information. The data structure of the arrays depends on the structure of the international meteorological code which the meteorological station uses. The most common meteorological codes are FM 12 Synop and METAR. They have the same indicators of instrument measurements, namely: wind speed and direction, air temperature, atmosphere pressure, humidity and cloudiness. The vector of instrument measurements is defined as function of time $t$

$$
A_{m}^{\tau}(t)=\left[\begin{array}{c}
v_{\text {wind }}(t), v_{r}(t), T_{\text {air }}(t) \\
p_{\text {air }}(t), \phi_{\%}(t),{ }_{\%} c(t)
\end{array}\right]
$$

where $v_{\text {wind }}$ is wind speed, $v_{r}$ is wind direction, $T_{a i r}$ is air temperature, $p_{\text {air }}$ is atmosphere pressure, $\varphi_{\%}$ is atmosphere humidity, $c_{\%}$ is atmosphere cloudiness.

A detailed description of integration of the longterm meteorological observations into system energy studies is presented in [13].

\section{B. Solar radiation}

A pair of mathematical models Iqbal-KastenCzeplak [14] is used to compute solar radiation. At the first stage, the parameters for clear sky conditions are calculated with the subsequent determination of the attenuation coefficients of solar radiation. Calculations are performed for the entire period of meteorological observations with a discrete step of one hour. The total number of states of solar radiation depends on the dimension of the initial array of climate information.

The resulting arrays of climate information are integrated into system energy research

\section{Example of Vietnamease climatic data processing}

The Ho Chi Minh city is chosen for research. There is a weather station Nyabe located $15 \mathrm{~km}$ far from the city. The weather station operates with FM 12 Synop format. There are 6 years of meteorological observations. The dimension of the initial array of information is more than 300000 measurements.

Figure 1 shows the average monthly solar radiation.

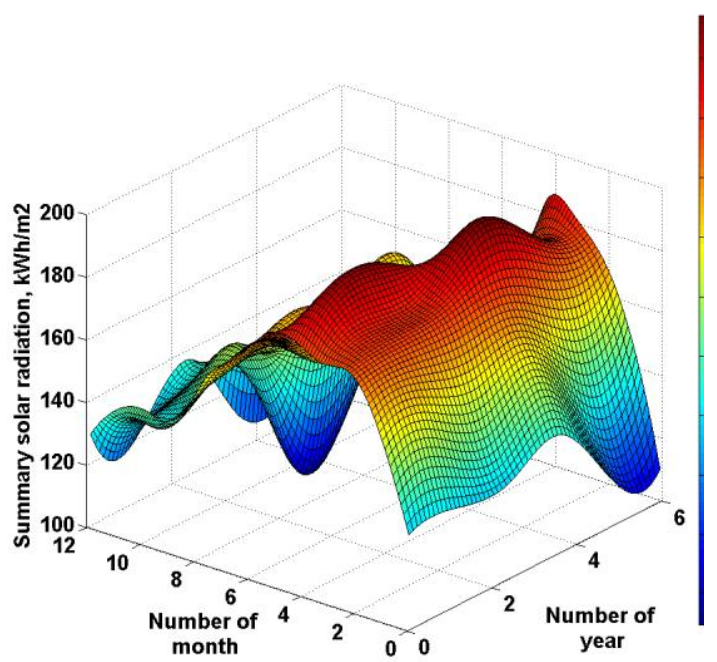

Fig. 1. Average monthly solar radiation at Ho Chi Minh city on the basis of 6 year observations

The change of the wind speed graph is shown in the Figure 2. Figure 3 shows the average monthly air temperature at the Ho Chi Minh city. 


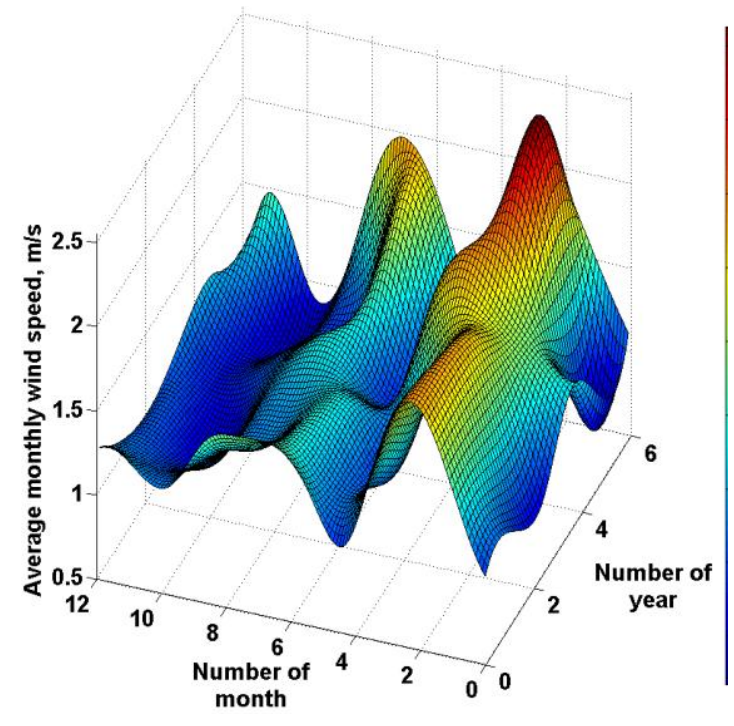

Fig. 2. Average monthly wind speed at Ho Chi Minh city on the basis of 6 year observations

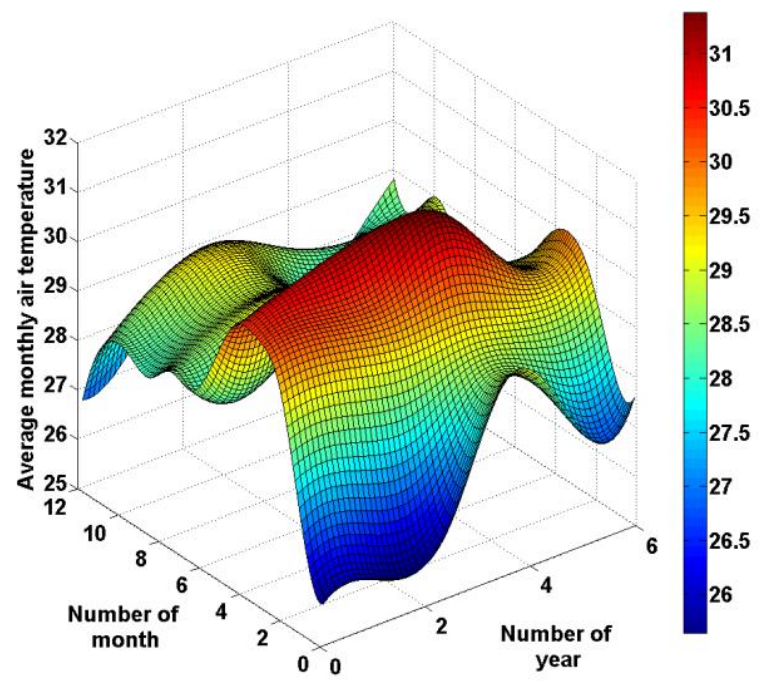

Fig. 3. Average monthly air temperature at Ho Chi Minh city on the basis of 6 year observations

\section{CONCLUSIONS}

Nowadays long-term energy system optimization models are frequently used in studies analysing the transition towards a sustainable energy system with an increased share of intermittent renewable energy sources. Highly variable and stochastic nature of renewable energy sources poses some challenges to long-term energy system optimization models to research the GEP problem due to using a low temporal resolution and neglecting the short-term dynamics. The common approach to withstand those challenges is the soft-linking of energy system models to a shortterm operational power system models. Such approach was proposed in [2] to investigate the future Vietnam electricity market in terms of supply-demand balance and how renewable energy sources could help to improve the performance of electricity market to 2030/2035.

The proposed in this paper MGEP model considers the fuel restrictions on the power generation and transmission network (only the power flow conservation) to measure the geographical impact of the generation additions. Its objectives are minimization of investment, operation and transmission costs, environmental impact, imports of fuel and unmet demand cost. Also the MGEP model takes into account the following types of constraints: flow balance constraints in the network with demand covering, power generation and transmission limit, generation and transmission investment, availability of local production of fossil fuels, system reliability requirements, maximum and minimum shares of RE resources, energy supply security requirements.

\section{ACKNOWLEDGMENT}

The authors especially thank the IES VAST for providing fund and creating favour in data collection during the implementation of the study.

This paper is developed as a subsidiary component of the study "Research on methodology and software to assess the power system reliability with consideration of renewable energy and other fuels for Vietnam power plants". Also, the work was carried out within the framework of the scientific project III.17.5 of the program of fundamental research of the SB RAS, No. AAAA-A17-117030310451-0.

\section{REFERENCES}

[1] Nguyen, Quoc Khanh, "Long term optimization of energy supply and demand in Vietnam with special reference to the potential of renewable energy," $\mathrm{PhD}$ diss., Universität Oldenburg, 2005.

[2] A. Edelev, H. N. Nguyen, and L. Q. Luu, "Estimating Solar Power Integration into Vietnam's Power Mix with the Combinatorial Modelling Approach," In Vth International workshop "Critical infrastructures: Contingency management, Intelligent, Agent-based, Cloud computing and Cyber security" (IWCI 2018), Atlantis Press, 2018.

[3] J. Després, N. Hadjsaid, P. Criqui, and I. Noirot, "Modelling the impacts of variable renewable sources on the power sector: Reconsidering the typology of energy modelling tools," Energy, vol. 80, pp. 486-495, 2015.

[4] M. Gargiulo and B. Ó. Gallachóir, "Long- term energy models: Principles, characteristics, focus, and limitations," WIREs Energy Environ., vol. 2(2), pp. 158-177, 2013.

[5] P. Das, J. Mathur, R. Bhakar, and A. Kanudia, "Implications of short-term renewable energy resource intermittency in long-term power system planning," Energy Strateg. Rev., vol. 22, pp.1-15, 2018

[6] N. E. Koltsaklis and A. S. Dagoumas, "State-of-the-art generation expansion planning: A review.," Appl. Energy, vol. 230, pp.563-589, 2018.

[7] J.L.C. Meza, M.B. Yildirim, and A.S. Masud, "A model for the multiperiod multiobjective power generation expansion problem," IEEE Trans. Power Syst., vol. 22(2), pp.871-878, 2007.

[8] H. Tekiner, D. W. Coit, and F. A. Felder, "Multi-period multi-objective electricity generation expansion planning problem with Monte-Carlo simulation," Electr. Pow. Syst. Res., vol. 80(12), pp. 1394-1405, 2010.

[9] A. Kies, B. Schyska, D. T. Viet, L. von Bremen, D. Heinemann, and S. Schramm, "Large-Scale Integration of Renewable Power Sources into the Vietnamese," Power System. Energy Procedia, vol. 125, pp.207-213, 2017.

[10] E. Noorollahi, D. Fadai, S. H. Ghodsipour, and M. A. Shirazi, "Developing a new optimization framework for power 
generation expansion planning with the inclusion of renewable energy - A case study of Iran," J. Renew. Sustain. Energy, vol. 9(1), p. 015901, 2017.

[11] M. M. Rienecker, M. J. Suarez, R. Gelaro, R. Todling, et al., "MERRA: NASA's Modern-Era Retrospective Analysis for Research and Applications," J. Clim, vol. 24(14) , pp. 36243648, 2011.

[12] R. Müller, U. Pfeifroth, C. Träger-Chatterjee, J. Trentmann, R. Cremer, "Digging the METEOSAT Treasure-3 Decades of Solar Surface Radiation,” Remote Sens. , vol. 7, pp. 8067 8101, 2015.

[13] D.N. Karamov, "Mathematical modeling of solar radiation based on open access long-term meteorological observation data," Bulletin of the Tomsk Polytechnic University, Geo Assets Engineering, vol. 328, no. 6, pp. 28-37, 2017. In Rus.

[14] D.N. Karamov, "Formation of initial meteorological arrays with the use of long-term series FM 12 Synop and METAR in systems energy studies," Bulletin of the Tomsk Polytechnic University, Geo Assets Engineering, vol. 329, no. 1, pp. 6988, 2018. In Rus. 